\title{
Inovação, persistência e criatividade superando barreiras no desenvolvimento de alimentos probióticos
}

\author{
Tiemy Rosana Komatsu, Flávia Carolina Alonso Buriti, Susana Marta Isay Saad* \\ Departamento de Tecnologia Bioquímico-Farmacêutica, Faculdade de Ciências Farmacêuticas, \\ Universidade de São Paulo
}

*Correspondência:

S. M. I. Saad

Departamento de Tecnologia

Bioquímico-Farmacêutica

Faculdade de Ciências Farmacêuticas

- Universidade de São Paulo

Av. Prof. Lineu Prestes, 580

05508-000 - São Paulo - SP, Brasil

E-mail: susaad@usp.br

\begin{abstract}
O propósito da administração de produtos probióticos é resultar em microbiota intestinal balanceada, a qual, por sua vez, terá um impacto favorável sobre a saúde do consumidor. Uma seleção adequada de cepas deve ser conduzida para o processamento de produtos alimentícios probióticos. Essa seleção visa garantir a sobrevivência desses microrganismos à passagem pelo trato gastrintestinal, após a manutenção de sua viabilidade no próprio produto-alvo, durante a sua elaboração e o seu armazenamento, bem como conferir propriedades tecnológicas adequadas a esse produto. O veículo alimentício escolhido para a incorporação de cepas probióticas deve ser cuidadosamente estudado para a seleção conveniente do par cepa probiótica-veículo, particularmente nos produtos fermentados, para os quais a multiplicação de probióticos pode resultar em características não peculiares ou mesmo indesejáveis ao produto. A verificação da compatibilidade e adaptabilidade entre as cepas selecionadas e os referidos veículos é fundamental. Esses pré-requisitos representam desafios tecnológicos significativos, uma vez que muitas bactérias probióticas são sensiveis à exposição a oxigênio, calor e ácidos. Diversos produtos lácteos probióticos, principalmente fermentados, e alguns não-lácteos, vêm sendo desenvolvidos. Os principais desafios encontrados no desenvolvimento e armazenamento desses produtos funcionais são discutidos no presente artigo.
\end{abstract}

Unitermos

- Probióticos

- Alimentos funcionais

- Lactobacillus

- Bifidobacterium

- Simbióticos

- Prebióticos

\section{INTRODUÇÃO}

O desenvolvimento de novos produtos alimentícios torna-se cada vez mais desafiador, à medida que procura atender à demanda dos consumidores por produtos que, concomitantemente, sejam saudáveis e atrativos. Conse- qüentemente, a alimentação de indivíduos com estilo de vida saudável tende a ser, um ato prazeroso e que ao mesmo tempo, visa a saúde e o bem estar.

Os efeitos benéficos de determinados tipos de alimentos sobre a saúde já são conhecidos há muito tempo. Alimentos funcionais são aqueles que, além de contribuírem 
com a nutrição, contêm substâncias que podem ser consideradas biologicamente ativas, produtoras de benefícios clínicos ou de saúde. A definição aceita (Stanton et al., 2005; Roberfroid, 2005) descreve os alimentos funcionais como 'alimentos para os quais pode ser satisfatoriamente demonstrado que eles afetam beneficamente uma ou mais funções do organismo, além de garantirem efeitos nutricionais adequados, conduzindo a uma melhoria do estado geral de saúde e bem estar e/ou a uma redução do risco de doenças' (European Commission Concerted Action on Functional Food Science in Europe, 1999). Esses alimentos possuem potencial para promover a saúde através de mecanismos não previstos na nutrição convencional, devendo ser salientado que esse efeito restringe-se à promoção da saúde e não à cura de doenças (Sanders, 1998). A incorporação da dieta a um estilo de vida saudável, uma vez que esta pode estar associada à prevenção de doenças e promoção da saúde, levou à criação de um mercado para esses produtos (Arvanitoyannis, HouwelingenKoukaliaroglou, 2005).

São vários os fatores que vêm estimulando o desenvolvimento de alimentos funcionais ao longo dos últimos anos. Dentre eles, destacam-se principalmente: o aumento da expectativa de vida em países desenvolvidos (cujas populações necessitarão de cuidados hospitalares por maior período de tempo), o elevado custo dos serviços de saúde, os avanços na tecnologia de alimentos e ingredientes, a necessidade que as instituições públicas de pesquisa têm em divulgarem os resultados de suas investigações e a maior cobertura dos diferentes tipos de mídia dada a essas descobertas e às questões de saúde (Arvanitoyannis, Houwelingen-Koukaliaroglou, 2005).

Um alimento funcional pode ser classificado de acordo com o alimento em si ou conforme os componentes bioativos nele presentes, como, por exemplo, os probióticos, as fibras, os fitoquímicos, as vitaminas, os minerais, as ervas, os ácidos graxos ômega $3(\omega-3)$, além de determinados peptídeos e proteínas (Arvanitoyannis, Houwelingen-Koukaliaroglou, 2005). Complementarmente, a fisiologia do intestino, assim como a composição e atividade do ecossistema microbiano responsável pela sua colonização, tem atraído um grandioso interesse para o desenvolvimento de alimentos funcionais, o que é revelado pelos recentes desenvolvimentos visíveis no mercado de probióticos, prebióticos e simbióticos (Roberfroid, 2005).

Os probióticos eram classicamente definidos como 'suplementos alimentares à base de microrganismos vivos que afetam beneficamente o animal hospedeiro, promovendo o balanço de sua microbiota intestinal' (Fuller, 1989). Diversas outras definições de probióticos já foram publicadas (Sanders, 2003). Entretanto, a definição atual- mente aceita internacionalmente é que eles são microrganismos vivos, administrados em quantidades adequadas, que conferem benefícios à saúde do hospedeiro (Food and Agriculture Organization of United Nations, World Health Organization, 2001; Sanders, 2003). Os prebióticos, por sua vez são atualmente definidos como 'ingredientes seletivamente fermentáveis que permitem modificações específicas na composição e/ou na atividade da microbiota gastrintestinal que resultam em benefícios ao bem estar e à saúde do hospedeiro' (Gibson et al., 2004; Roberfroid, 2007; Wells, Saulnier, Gibson, 2008).

Para garantir um efeito contínuo no organismo humano, os probióticos devem ser ingeridos diariamente. Alterações favoráveis na composição da microbiota intestinal, capazes de garantir a manutenção das concentrações ativas fisiologicamente (quantidade intestinal de $10^{6}$ a $10^{7} \mathrm{ufc} \mathrm{g}^{-1}$ ) in vivo, foram observadas com doses de $100 \mathrm{~g}$ de produto alimentício contendo $10^{8}$ a $10^{9}$ unidades formadoras de colônias (ufc) de microrganismos probióticos ( $10^{6}$ a $10^{7} \mathrm{ufc} \mathrm{g}^{-1}$ de bioproduto). No caso dos prebióticos, doses diárias a partir de 4 a $5 \mathrm{~g}$ até $20 \mathrm{~g}$ de inulina e/ou oligofrutose, administradas durante pelo menos 15 dias, são eficientes para garantir o estímulo da multiplicação de bifidobactérias no cólon (Charteris et al., 1998a; Niness, 1999; Roberfroid, 1999; Shah, 2000; Vinderola, Reinheimer, 2000, 2003).

No Brasil, a Comissão Tecnocientífica de Assessoramento em Alimentos Funcionais e Novos Alimentos, instituída junto à Câmara Técnica de Alimentos (Brasil, 1999) tem avaliado os produtos com alegações de propriedades funcionais e/ou de saúde aprovados no país. Anteriormente, a referida Comissão recomendou que um alimento funcional probiótico deveria apresentar uma concentração mínima de $10^{6} \mathrm{ufc} \mathrm{g}^{-1}$ dentro do prazo de validade do produto (Agência Nacional de Vigilância Sanitária, 2001). Atualmente, a recomendação é com base na porção diária de microrganismos viáveis que devem ser ingeridos, sendo o mínimo estipulado de $10^{8}$ a $10^{9}$ ufc dia ${ }^{-1}$ (Agência Nacional de Vigilância Sanitária, 2007). É necessário destacar que no período em que as recomendações para alimentos probióticos foram revistas pela Comissão, houve um aumento do número de produtos probióticos disponíveis no mercado brasileiro. Dessa forma, também seria fundamental considerar a somatória dos microrganismos viáveis ingeridos nos diversos produtos probióticos consumidos ao longo do dia. Entretanto, é importante, ainda, ressaltar que a maior disponibilidade de dados sobre as concentrações bacterianas efetivas indica, claramente, que a concentração probiótica necessária varia em função da cepa e do efeito desejado sobre a saúde (Champagne, Gardner, Roy, 2005).

Dentre os microrganismos probióticos mais utilizados, destacam-se várias cepas de lactobacilos e bifido- 
bactérias. De acordo com Shah (2007), 56 espécies são reconhecidas como pertencentes ao gênero Lactobacillus e 29 espécies são classificadas como Bifidobacterium, embora poucas sejam as cepas com efeito probiótico bem documentado. Diversos efeitos benéficos atribuídos aos probióticos foram amplamente discutidos em outra revisão (Saad, 2006). De modo geral, lactobacilos podem colaborar na digestão da lactose em indivíduos com intolerância a esse dissacarídeo, reduzir a constipação e a diarréia infantil, ajudar na resistência a infecções por salmonela, prevenir a "diarréia do viajante" e aliviar a síndrome do intestino irritável. Bifidobactérias são conhecidas por estimularem o sistema imunológico, produzirem vitamina $\mathrm{B}$, inibirem a multiplicação de patógenos, reduzirem a concentração de amônia e colesterol no sangue e ajudarem a restabelecer a microbiota normal após tratamento com antibióticos. Assim sendo, esses microrganismos são comumente utilizados em intervenções dietéticas que visam à melhoria da saúde dos indivíduos (Manning, Gibson, 2004; Picard et al., 2005; Leahy et al., 2005; Novik et al., 2006).

O propósito da administração de produtos probióticos é resultar em uma microbiota intestinal balanceada e, conseqüentemente, ter um impacto favorável sobre a saúde do consumidor (Tannock, 1998). Dessa forma, uma seleção adequada de cepas deve ser conduzida para o processamento de produtos lácteos probióticos (MattilaSandholm, Mättö, Saarela, 1999; Vinderola, Reinheimer, 2003), uma vez que é fundamental a sobrevivência das bactérias probióticas no produto alimentício.

Cepas selecionadas com base em sua resistência a ácidos podem ser úteis em aplicações probióticas e apresentar sobrevivência aumentada, tanto nas condições ambientais do hospedeiro quanto em produtos alimentícios (Ross, Desmond, Stanton, 2005).

Além de boa viabilidade no intestino, as propriedades tecnológicas são pré-requisitos para a utilização potencial de culturas probióticas em queijos (Kask et al., 2003) e outros produtos alimentícios. Esse fato deve ser considerado na escolha do par cepa probiótica-veículo, particularmente nos produtos fermentados. Nesses produtos, a multiplicação de cepas probióticas pode resultar em características não peculiares ou mesmo indesejáveis. Assim, a utilização de veículos alimentícios apropriados para as cepas probióticas é fundamental, bem como a verificação da compatibilidade e adaptabilidade entre as cepas selecionadas e os referidos veículos.

Produtos alimentícios como os laticínios contribuem para a sobrevivência dos probióticos ao suco gástrico, particularmente por seu efeito tamponante e protetor (Ross, Desmond, Stanton, 2005). De fato, o aumento do $\mathrm{pH}$ e da sobrevivência de algumas espécies de Lactobacillus e de
Bifidobacterium em suco gástrico e em meio de cultura simulando o suco gástrico adicionados de leite ou de proteínas do leite foram descritos (Charteris et al., 1998b). A indústria de laticínios, em particular, encontrou nas culturas probióticas uma ferramenta para o desenvolvimento de novos produtos (Champagne, Gardner, Roy, 2005). Conseqüentemente, inúmeros laticínios probióticos são disponíveis comercialmente e a variedade desses produtos continua em expansão (Stanton et al., 2003).

Entretanto, é importante salientar que um produto probiótico deve conter uma ou mais cepas definidas e bem caracterizadas, no sentido de compreender os fatores determinantes sobre a funcionalidade probiótica e os benefícios do hospedeiro, já que os efeitos probióticos são específicos para determinadas cepas em especial. A seleção de cepas probióticas deve ser direcionada aos efeitos desejáveis para o produto específico ou para a população-alvo daquele produto. Uma estratégia é adicionar diferentes cepas com diferentes efeitos clínicos atribuídos. A validação da função probiótica ou o monitoramento do impacto probiótico de uma preparação de microrganismos com uma composição desconhecida é cientificamente inaceitável (Sanders, 2003; Champagne, Gardner, Roy, 2005).

Além da seleção adequada de cepas, o método de sua preparação é de fundamental importância. Pouca atenção tem sido dispensada ao efeito da tecnologia e do armazenamento sobre atributos probióticos específicos. Assim, todos os aspectos relacionados à obtenção das cepas probióticas, para sua posterior adição aos produtos alimentícios, deverão ser estudados cuidadosamente, uma vez que as tecnologias de fermentação, de secagem e de microencapsulação das culturas influenciam significativamente a funcionalidade dos probióticos (Mattila-Sandholm et al., 2002; Champagne, Gardner, Roy, 2005).

\section{O papel das culturas láticas e probióticas nos produtos lácteos. Aspectos tecnológicos gerais sobre a elaboração de produtos lácteos probióticos}

Segundo Leroy e De Vuyst (2004), uma cultura starter pode ser definida como 'uma preparação microbiana contendo um grande número de células de pelo menos um microrganismo a ser adicionado à matéria-prima para produzir um produto alimentício fermentado'. O grupo das bactérias láticas ocupa um papel central nessa técnica, acelerando e conduzindo o processo fermentativo. A adição direta de culturas selecionadas tem representado um avanço na elaboração de produtos fermentados, resultando em um alto grau de controle sobre o processo fermentativo e de padronização do produto final (Leroy, De Vuyst, 2004). 
O metabolismo de bactérias láticas e a interação entre as cepas selecionadas em leites fermentados e iogurtes são responsáveis pela produção de ácido lático, levando à coagulação das proteínas do leite e à produção de diversos compostos. Variáveis como a temperatura, o $\mathrm{pH}$, a presença de oxigênio e a composição do leite contribuem para as características peculiares de um produto específico. De acordo com a temperatura e o tempo de fermentação, são formados diferentes produtos metabólicos (Ostlie, Treimo, Narvhus, 2005). A temperatura de fermentação afeta, primariamente, a multiplicação bacteriana e, conseqüentemente, a estrutura e o sabor do produto (Kristo, Biliaderis, Tzanetakis, 2003).

A conversão de lactose em ácido lático é resultante da multiplicação das culturas no leite. Essa ocorre geralmente em velocidade muito lenta, não garantindo o $\mathrm{pH}$ adequado em um tempo considerado relativamente curto para a obtenção de certos derivados. Esse fato é observado particularmente para a obtenção de leites fermentados e queijos, produtos que necessitam de leite com $\mathrm{pH}$ adequado para que ocorra a coagulação. Durante a elaboração de leites fermentados, o efeito do $\mathrm{pH}$ sobre a coagulação é direto (ao atingir $\mathrm{pH} 4,3-4,5)$, enquanto na produção de queijos esse efeito é indireto, atuando em conjunto com a temperatura na promoção da atividade enzimática do coagulante.

Alternativamente, as culturas starter convencionais podem ser substituídas ou associadas a culturas probióticas. Segundo Parvez et al. (2006), a ação dos probióticos nas fermentações durante a elaboração de produtos lácteos pode resultar nas seguintes características: 1) conservação do leite, resultante da produção de ácido lático e, possivelmente, de outros compostos antimicrobianos; 2) produção de compostos aromáticos (como o acetaldeído em iogurte e queijo) e outros metabólitos (como os polissacarídeos extracelulares), os quais irão suprir o produto com as propriedades sensoriais desejadas pelo consumidor; 3 ) melhoria do valor nutricional do produto alimentício através, por exemplo, da liberação de aminoácidos livres ou da síntese de vitaminas e 4) fornecimento de propriedades terapêuticas ou profiláticas. Entretanto, é importante salientar que as três primeiras características mencionadas estão relacionadas também à presença das culturas starter e que as culturas probióticas podem ou não desenvolver tais características.

As bactérias probióticas utilizadas na produção em escala industrial e de processamento devem ser apropriadas para cada tipo de produto e manter-se com boa viabilidade durante o armazenamento. Esses pré-requisitos representam desafios tecnológicos significantes, uma vez que muitas bactérias probióticas são sensíveis à exposição a oxigênio, calor e ácidos. Conseqüentemente, em alimentos fermentados, o pH tende a ser bastante reduzido e o desem- penho desses microrganismos é baixo. Por esse motivo, os produtos com menor vida de prateleira, como o iogurte e leites fermentados, são os mais comumente utilizados como veículos de probióticos, apesar de já existirem produtos probióticos com maior vida de prateleira, como o queijo tipo Cheddar (Stanton et al., 2005).

Uma excelente alternativa para aumentar a multiplicação de um probiótico é a adição de outra espécie probiótica em co-cultura. Entretanto, deve-se verificar a compatibilidade entre as culturas a serem empregadas. Gomes e Malcata (1998) demonstraram que Bifidobacterium lactis multiplicaram-se mais em co-cultura com Lactobacillus acidophilus. O estímulo da multiplicação de Bifidobacterium bifidum por $L$. acidophilus também foi descrito (Svensson, 1999).

Segundo Vinderola, Mocchiutti e Reinheimer (2002), as possíveis interações entre as espécies empregadas para a produção de alimentos fermentados devem ser levadas em consideração para selecionar a combinação capaz de oferecer o melhor resultado no processo tecnológico e garantir a viabilidade das células durante o armazenamento refrigerado. Entretanto, é importante salientar que o controle da proporção das diferentes cepas pode ser complicado e que a interação entre elas pode ser influenciada pelo meio (Champagne, Gardner, Roy, 2005). Conseqüentemente, a combinação de diferentes cepas probióticas e/ou starter deve ser testada especificamente para o produto a ser usado como veículo para aquele conjunto de cepas, bem como a proporção entre elas durante todas as etapas, desde a sua elaboração até o final de seu armazenamento.

Muitos estudos realizados com adição de culturas probióticas durante a elaboração de diversos produtos lácteos, principalmente fermentados, e alguns não lácteos foram realizados, visando concentrações superiores a $6 \log$ ufc g-1 ou $\mathrm{mL}^{-1}$ de produto, sem alterações importantes nas suas características. De modo geral, a maior preocupação é no sentido de que a adição de probióticos aos produtos alimentícios possa afetar suas propriedades sensoriais. De fato, segundo Champagne, Gardner e Roy (2005), a introdução bem sucedida de um produto no mercado estará diretamente relacionada com o seu aroma, sabor e textura. Assim sendo, nos próximos itens serão abordados alguns estudos realizados em diferentes categorias de produtos alimentícios suplementadas com culturas probióticas.

\section{O leite, iogurtes e leites fermentados como produtos probióticos}

O iogurte é um produto elaborado com culturas ativas de bactérias láticas que fermentam o creme e/ou o leite, metabolizando parte da lactose presente a ácido lático. Durante esse processo, que normalmente ocorre em um 
tempo inferior a 4 a 5 horas de incubação em temperaturas de 40 a $44{ }^{\circ} \mathrm{C}$, o leite líquido tem a sua consistência alterada, em virtude da coagulação de suas proteínas. A redução de $\mathrm{pH}$ a 5,1-5,2, resultante da produção de ácido lático durante a fermentação, causa a desestabilização das micelas de caseína e a coagulação completa ocorre a um $\mathrm{pH}$ de 4,6. Quando o pH desejado é atingido, o leite coagulado é resfriado rapidamente, para que a fermentação seja praticamente interrompida (Van de Water, 2003).

Diferentemente do leite fermentado, o iogurte é produzido com a utilização de cepas de Lactobacillus delbrueckii susbp. bulgaricus e de Streptococcus thermophilus. Essas bactérias utilizam o leite como nicho ecológico. Além disso, existe uma relação simbiótica entre esses dois microrganismos, na qual cada um deles estimula a multiplicação do outro. Assim, L. delbrueckii ssp. bulgaricus libera aminoácidos e peptídios das proteínas do leite, o que possibilita a multiplicação de $S$. thermophilus nos primeiros estágios da fermentação. S. thermophilus, por sua vez, produz ácido fórmico, o qual estimula a multiplicação de L. delbrueckii ssp. bulgaricus, diminuindo o tempo de fermentação e conferindo ao produto características peculiares (Van de Water, 2003; Hols et al., 2005).

Apesar de não sobreviverem às condições do trato gastrintestinal em concentrações compatíveis para exercerem efeitos probióticos in vivo, existe uma grande discussão atualmente sobre o caráter probiótico dos microrganismos do iogurte, uma vez que $L$. delbrueckii ssp. bulgaricus e $S$. thermophilus melhoram a digestão de lactose e eliminam sintomas de intolerância a esse dissacarídeo (Vinderola, Reinheimer, 2003; Guarner et al., 2005). A esse respeito, Vinderola e Reinheimer (2003) concluíram que, tanto no caso das culturas probióticas quanto das culturas starter, as características probióticas e a resistência às barreiras biológicas são variáveis para diferentes espécies e mesmo para diferentes cepas de uma mesma espécie. Segundo os autores, quando ambos os grupos são utilizados em conjunto o 'valor probiótico' do produto alimentício deve levar em conta a possível contribuição das cepas starter de bactérias láticas envolvidas.

Alguns produtos à base de iogurte foram reformulados para incluir, além das culturas convencionais de iogurte, culturas de L. acidophilus e de Bifidobacterium spp. (conhecidas como culturas AB). Esses produtos passaram a ser denominados de bio-iogurtes. Durante o seu processo de elaboração, as culturas probióticas podem ser adicionadas antes da fermentação, em conjunto com as culturas convencionais do iogurte, ou após a fermentação (LourensHattingh, Viljoen, 2001). Entretanto, cada condição de cultivo deve ser previamente testada, uma vez que cada cepa probiótica tem um comportamento peculiar em uma situação específica.

Nos últimos dez anos, período em que os produtos suplementados com culturas probióticas passaram a assumir um papel de importância no universo científico, muita pesquisa com probióticos tem sido voltada para leites fermentados e iogurtes, sendo estes os produtos probióticos que predominam no comércio mundial. Entretanto, é importante salientar que diversos fatores podem prejudicar a multiplicação das bactérias probióticas durante a elaboração desses produtos, bem como a sobrevivência desses microrganismos durante o período de armazenamento.

Svensson (1999) destacou os principais fatores a serem considerados durante a fabricação de leites fermentados e iogurtes probióticos, entre eles a composição do meio de fermentação e a quantidade de oxigênio dissolvido. Assim, a adição de hidrolisados protéicos de caseína ou de soro, extrato de levedura, glicose, vitaminas e minerais (sempre em proporções compatíveis com a legislação) pode estimular a multiplicação e a sobrevivência das culturas probióticas e desenvolver a textura dos produtos. A adição de proteínas resulta, também, no aumento da capacidade tamponante do leite fermentado e pode retardar a queda de $\mathrm{pH}$ e impedir modificações desse parâmetro durante $o$ armazenamento do produto, permitindo, assim, maior sobrevivência das cepas probióticas (Svensson, 1999; Lourens-Hattingh, Viljoen, 2001).

O leite fermentado probiótico pode ser definido como um leite fermentado que traz benefícios ao restabelecer um ecossistema ótimo da microbiota intestinal ou ao melhorar o balanço microbiano (Kalantzopoulos, 1997). A produção de leite fermentado probiótico é um grande desafio, uma vez que, o leite não é um meio adequado para a multiplicação de microrganismos probióticos (Vinderola et al., 2000a; Lucas et al., 2004; Ostlie, Treimo, Narvhus, 2005). Apesar de ser um meio rico do ponto de vista nutricional, o leite como meio de cultivo para as bactérias probióticas resulta em sua multiplicação lenta, em virtude, principalmente, da ausência de atividade proteolítica (Klaver, Kingman, Weerkamp, 1993; Oliveira, Damin, 2003). A incorporação de micronutrientes, como peptídios e aminoácidos, e de outros fatores de crescimento pode ser necessária para reduzir o tempo de fermentação e propiciar viabilidade às bactérias probióticas (Oliveira et al., 2002).

Também existe a possibilidade de uma adição complementar de bactérias do iogurte, L. delbrueckii ssp. bulgaricus e Streptococcus thermophilus, para melhorar o processo de fermentação durante a fabricação de leites fermentados contendo probióticos (Oliveira, Damin, 2003). Almeida, Bonassi e Roça (2001) verificaram um índice de proteólise mais elevado em bebidas lácteas fermentadas fabricadas com a cultura mista ABY, composta de $L$. delbrueckii ssp. bulgaricus, $S$. 
thermophilus, Bifidobacterium e L. acidophilus, em comparação às bebidas fabricadas apenas com a adição dos microrganismos tradicionais do iogurte. Segundo alguns autores, esse aumento na proteólise do produto pode resultar em uma melhor sobrevivência dos microrganismos probióticos, decorrente da produção de aminoácidos essenciais por $L$. delbrueckii ssp. bulgaricus (Dave, Shah, 1998; Almeida, Bonassi, Roça, 2001; Donkor et al., 2006).

Por outro lado, L. delbrueckii ssp. bulgaricus é um microrganismo oriundo do leite que compete com os lactobacilos probióticos durante a fermentação. Além disto, durante o armazenamento sob refrigeração, $L$. delbrueckii ssp. bulgaricus produz peróxido de hidrogênio e ácido lático, que também afetam a sobrevivência de bactérias probióticas. Outro inconveniente é a pós-acidificação do produto. Entretanto, quando a cultura starter está ausente de L. delbrueckii ssp. bulgaricus, o tempo de fermentação é de duas a três vezes maior, já que a ação proteolítica dessa bactéria estimula a acidificação por S. thermophilus (Dave, Shah, 1998; Oliveira, Damin, 2003; Lucas et al., 2004). Apesar do tempo de fermentação maior utilizando apenas S. thermophilus como cultura starter na elaboração de leites fermentados probióticos, esse microrganismo não tem sido descrito como inibitório para microrganismos probióticos e pode, inclusive, estimular a sua multiplicação, devido ao consumo de oxigênio (Svensson, 1999). Com o intuito de se superar o problema da pós-acidificação a tendência é utilizar a cultura mista denominada ABT, a qual contém L. acidophilus, bifidobactéria e $S$. thermophilus como starter (Dave, Shah, 1998; Zacarchenco, Massaguer-Roig, 2004).

Em alguns casos, quando os lactobacilos não se multiplicam de maneira satisfatória, pode-se aumentar a quantidade inoculada ou fortificar o leite com aditivos capazes de promover uma melhor multiplicação. Esses aditivos incluem, entre outros, suco de tomate, hidrolisado de caseína, casitona, proteína de soro de leite, polpa de mamão e açúcares simples fermentáveis (LourensHattingh, Viljoen, 2001; Stanton et al., 2003). Muitas cepas de L. acidophilus não conseguem se multiplicar no leite e quase não sobrevivem em produtos fermentados e, desta maneira, deve-se considerar a escolha da cepa mais adequada para cada tipo de produto (Kalantzopoulos, 1997).

Ostlie, Helland e Narvhus (2003) observaram que a multiplicação de L. acidophilus 1748, L. acidophilus La5, Lactobacillus reuteri SD 2112 e Bifidobacterium animalis $\mathrm{Bb} 12$ era maior quando se adicionava triptona ao leite. No caso de Lactobacillus rhamnosus GG, os autores observaram que a adição de frutose como suplemento resultou em uma multiplicação satisfatória do microrganismo para a obtenção de um leite fermentado probiótico. Um menor tempo de fermentação até se atingir um valor de $\mathrm{pH}$ de 4,5, em iogurtes suplementados com concentrado protéico de soro de leite (WPC), soro em pó, triptona e hidrolisado ácido de caseína, quando comparado com o iogurte controle e com aquele suplementado com cisteína também foi relatado (Dave, Shah, 1998).

Faria, Benedet e Le Guerroue (2006) utilizaram Lactobacillus casei na fermentação do leite de búfala com diferentes concentrações de açúcar, submetidos a diferentes tempos de fermentação e temperaturas de armazenamento. Os autores concluíram que o leite de búfala fermentado pode ser elaborado por fermentação durante 22 a 24 horas, com concentração de açúcar variando entre 10 e 14\%, e estocado entre 5 e $10^{\circ} \mathrm{C}$, durante 30 dias. Os autores também verificaram que o tempo de fermentação de 24 horas foi o mais adequado, por apresentar maior viabilidade de $L$. casei e que a variação do $\mathrm{pH}$ e da acidez foi influenciada principalmente pelo tempo de estocagem e, em menor proporção, pela temperatura de armazenamento. Naquele estudo, a variação da viabilidade de L. casei foi influenciada exclusivamente pela acidez.

Particularmente no caso das bifidobactérias, esses microrganismos não são muito bem adaptados ao leite fermentado e sofrem com a presença de oxigênio (Kalantzopoulos 1997; Dave, Shah, 1998; Stanton et al., 2003). Por este motivo, um critério de seleção importante para certas cepas é a multiplicação e a sobrevivência sob condições de acidificação e aerobiose (Kalantzopoulos, 1997). Uma das alternativas para se aumentar a multiplicação dessas bactérias em leites é, além da suplementação com fatores de crescimento, a adição de fatores bifidogênicos ou prebióticos (Tamime, Marshall, Robinson, 1995).

Os prebióticos mais utilizados como ingredientes funcionais em produtos lácteos fermentados são os frutanos tipo inulina e os frutooligossacarídeos (FOS), uma vez que as bifidobactérias fermentam esses oligossacarídeos preferencialmente a outras fontes de carboidratos (Fooks, Fuller, Gibson, 1999; Martinez-Villaluenga et al., 2006; Roberfroid, 2007). No entanto, outras cepas probióticas, além das de bifidobactérias, também podem utilizar FOS e/ou inulina como fontes de energia (Kaplan, Hutkins, 2000; Makras, Van Acker, De Vuyst, 2005). Desai, Powell e Shah (2004) observaram que sete cepas de Lactobacillus - L. casei (ASCC 1520, 290 e 279 e CSCC 2607), L. paracasei ASCC 292, L. rhamnosus ASCC 1521 e L. zeae ATCC 15820 - alcançaram melhor multiplicação e viabilidade em leite desnatado reconstituído suplementado com $5 \%$ de inulina $\left(\mathrm{p} . \mathrm{v}^{-1}\right)$. Capela, Hay e Shah (2006) verificaram que a adição de $2 \%$ de cada uma das fibras inulina, amido resistente de milho e, particularmente, oligofrutose aumentaram a viabilidade das cepas L. acidophilus 33200 , L. casei 279, Bifidobacterium longum 536 e L. rhamnosus GG em iogurtes, quando comparado ao iogurte controle 
sem a adição de fibras, durante quatro semanas de armazenamento a $4{ }^{\circ} \mathrm{C}$.

Paralelamente, as condições de processamento e de armazenamento do iogurte ou leite fermentado podem interferir, de maneira considerável, na disponibilidade dos prebióticos FOS e inulina para a fermentação por bactérias probióticas, em particular pela alteração da solubilidade desses oligossacarídeos em diferentes temperaturas (Kim, Faqih, Wang, 2001; Van Loo, 2004). Thamer e Penna (2005) não observaram o estímulo da multiplicação de bifidobactérias com o aumento da concentração de FOS em bebidas lácteas fermentadas. Naquele estudo, a ausência do efeito prebiótico no produto foi atribuída ao tratamento térmico prolongado utilizado na elaboração das bebidas lácteas.

Os oligossacarídeos das leguminosas, conhecidos como $\alpha$-galactosídeos ou oligossacarídeos da família da rafinose (RFOs), também podem ser utilizados pelas bifidobactérias (Martínez-Villaluenga et al., 2005). Assim, a adição de RFOs ao leite aumentou a população de $B$. lactis $\mathrm{Bb} 12$ (atualmente classificada como B. animalis) ao final do tempo de fermentação, em comparação com o controle, enquanto que para Lacidophilus não houve diferença na viabilidade com a suplementação. Os RFO aumentaram a taxa de acidificação e, conseqüentemente, o tempo de coagulação foi diminuído, o que resultou em melhoria nas características de textura dos produtos fermentados (Martinez-Villaluenga et al., 2006).

Adicionalmente, proteínas e peptídios originários da dieta, de secreções pancreáticas ou produzidos por bactérias também podem, embora em menor escala que os oligossacarídeos, ser utilizados pelos probióticos (Manning, Gibson, 2004).

Em geral, bifidobactérias se desenvolvem melhor em meios sintéticos do que em leite. Contudo, esses meios são caros para a multiplicação dessas bactérias em grande escala, além de causarem sabores desagradáveis nos produtos finais. Assim, a melhoria nas condições de multiplicação para diferentes linhagens de bifidobactérias no leite, por exemplo, pela adição de fontes de nitrogênio ou substâncias que diminuam o potencial redox do meio, e a seleção de linhagens menos exigentes são alternativas propostas para superar esses problemas (Dave, Shah, 1998; Gomes, Malcata, 1999).

A suplementação de leite fermentado com ingredientes nutracêuticos (ácidos graxos $\omega$-3, isoflavonas e fitoesteróis) estimulou a atividade de culturas probióticas de Bifidobacterium infantis, além da sua contribuição no aumento do valor nutricional do produto (Awaisheh, Haddadin, Robinson, 2005). A baixa taxa de sobrevivência de $B$. bifidum, B. breve, B. infantis e B. longum, em iogurtes armazenados sob refrigeração por 28 dias, foi relatada. Entretanto, iogurtes contendo B. animalis apresentaram maior sobrevivência. Com o intuito de se produzir maior quantidade de oligossacarídeos, reter a atividade da lactase e garantir maior sobrevivência durante a produção e o período de armazenamento, recomendou-se a utilização, respectivamente, de cepas de $B$. infantis, $B$. breve e $B$. animalis (Lamoureux, Roy, Gauther, 2002).

Diversas pesquisas têm focado a proteção e viabilidade das culturas probióticas durante a produção, armazenamento e passagem do produto probiótico pelo trato gastrintestinal. Os estudos têm mostrado que as culturas podem ser significativamente protegidas através da técnica de microencapsulação e de imobilização em uma série de substratos, que incluem proteínas do leite e carboidratos complexos (prebióticos) (Ross, Desmond, Stanton, 2005).

A técnica de microencapsulação ou imobilização pode conferir uma proteção às bifidobactérias sensíveis ao pH ácido e também aumentar sua sobrevivência durante a vida-de-prateleira do iogurte, assim como durante a sua passagem pelo trato gastrintestinal. O método da imobilização mais comumente utilizado envolve o preparo de cápsulas com hidrocolóide. Esse método consiste, simplesmente, da preparação de uma solução de hidrocolóides, onde são adicionados os microrganismos, com posterior extrusão da suspensão celular através de uma agulha de seringa. Desse modo, formam-se gotículas que caem livres em uma solução de endurecimento ou banho de fixação. O veículo mais utilizado para a técnica de imobilização é o polissacarídeo alginato de sódio, que forma um gel em contato com cálcio e outros cátions multivalentes. As partículas de alginato são estáveis sob condições de baixo $\mathrm{pH}$ (Krasaekoopt, Bhabdari, Deeth, 2003).

Capela, Hay e Shah (2006) observaram melhor sobrevivência de probióticos microencapsulados $(2$ cepas de L. acidophilus, 4 de L. casei, 1 de L. rhamnosus e 6 de Bifidobacterium spp.), durante o armazenamento de iogurtes liofilizados por 6 meses em temperaturas de 4, $21 \mathrm{e}$ $37^{\circ} \mathrm{C}$. Os autores observaram, ainda, que a adição de crioprotetores e de prebióticos não melhorou a viabilidade dos probióticos. Entretanto, no estudo de Grosso e FavaroTrindade (2004) a matriz de alginato falhou como barreira de proteção a $B$. lactis, quando esse microrganismo foi incorporado em iogurtes. Por outro lado, os autores observaram uma boa viabilidade de $B$. lactis e de $L$. acidophilus em leite e em leite acidificado, tanto na forma livre como imobilizada em alginato de cálcio. Os autores concluíram que a imobilização de $B$. lactis em alginato de cálcio não funcionou como barreira efetiva contra a presença prejudicial das bactérias tradicionais do iogurte. 


\section{Os queijos como produtos probióticos}

Os queijos são produtos com características peculiares que conferem proteção às bactérias probióticas contra a ação do oxigênio, baixo $\mathrm{pH}$ e sais biliares, durante a sua passagem pelo trato gastrintestinal. Esse conjunto de características, o qual inclui, entre outros, $\mathrm{pH}$ próximo ao neutro, atividade de água normalmente elevada (dependendo, obviamente, da quantidade de sal do queijo e das condições de maturação, no caso de ser um produto maturado), matriz sólida (que facilita o "encaixe da bactéria") e concentração relativamente elevada de gordura, leva a crer que esses produtos sejam mais adequados como veículos para os probióticos que leites fermentados e iogurtes (Gardiner et. al., 1998; Stanton et. al., 1998; Daigle et al., 1999; Corbo et al., 2001; Heller et al., 2003; Boylston et al., 2004; Bergamini et al., 2005).

Diversos tipos de queijo foram testados como veículos para cepas probióticas de Lactobacillus e de Bifidobacterium: cheddar ou semelhante ao cheddar (Dinakar, Mistry, 1994; Stanton et al., 1998; Gardiner et al., 1998; Gardiner et al., 1999; Daigle et al., 1999; Gardiner et al., 2002; Mc Brearty et al., 2001), cottage (Blanchette et al., 1996), Crescenza (Gobbetti et al., 1997; Burns et al., 2008), Gouda (Gomes, Vieira, Malcata, 1998), petit-suisse (Maruyama et al., 2006; Cardarelli et al., 2008), queijos frescos (Roy, Mainville, Mondou, 1997; Vinderola et al., 2000b), incluindo o minas frescal (Buriti et al., 2005; Buriti, Rocha, Saad, 2005; Souza et al., 2008) e o queijo fresco cremoso (Buriti, Cardarelli, Saad, 2007a; Buriti et al., 2007b), entre outros (Ghoddusi, Robinson, 1996; Menéndez et al., 2000; Ross et al., 2000; Corbo et al., 2001; Gobbetti et al., 2002; Heller et al., 2003; Boylston et al., 2004; Bergamini et al., 2005).

Assim como ocorre com praticamente todos os outros produtos alimentícios, os principais pontos relacionados a modificações nos processos de elaboração de queijos podem sucumbir quanto à sua eficiência, qualidade, sabor, segurança, saúde e nutrição (Ross et al., 2000). No caso específico dos queijos elaborados com a adição de culturas probióticas, o produto deve garantir uma concentração razoável de probióticos no momento do consumo para que, ao final do trato gastrintestinal, se apresente em doses benéficas à saúde. Estudos com diferentes tipos de queijos mostraram variações em seu período máximo de armazenamento, no sentido de garantir a viabilidade das bactérias probióticas.

Assim, o queijo tipo cheddar apresentou populações de bifidobactérias acima de $10^{6} \mathrm{ufc} \mathrm{g}^{-1}$, quando armazenado por até 12 semanas (Daigle et al., 1999). A adição de Lactobacillus helveticus WSU19 ao mesmo tipo de queijo contribuiu para uma melhoria do sabor do produto após
6 meses de armazenamento (Drake et al., 1996). O queijo cheddar contendo as cepas probióticas de L. paracasei $(2$ cepas) e Enterococcus faecium mostraram possuir melhor capacidade tamponante que o iogurte frente à exposição ao suco gástrico, conferindo uma melhor proteção à cultura probiótica, mesmo após, respectivamente, 5 e 15 meses de fabricação (Stanton et al., 1998; Gardiner et al., 1998; Gardiner et al., 1999). Por outro lado, as cepas de $L$. salivarius testadas não sobreviveram ao processo de maturação do queijo (Gardiner et al., 1998). Essas constatações reforçam a necessidade de se estudar cada cepa, em particular, em produtos alimentícios específicos candidatos a serem usados como veículos.

Gardiner et al. (2002) estudaram a utilização de uma cultura submetida à secagem em spray-dryer na produção de queijo cheddar probiótico. Os autores relataram que a população inicial (dia 0 ) de $L$. paracasei NFBC 338 passou de $2 \times 10^{7}$ ufc g $^{-1}$ para 7,7 x $10^{7}$ ufc g $^{-1}$ após 3 meses de maturação do queijo. Resultados de Ong, Henriksson e Shah (2006), comparando queijos probióticos com o controle, também mostraram que o queijo cheddar é um veículo efetivo de microrganismos probióticos. Por outro lado, em queijo Cottage, $B$. infantis sobreviveu bem nos 10 primeiros dias de armazenamento, não sendo detectada aos 28 dias (Blanchette et al., 1996).

A incorporação de três cepas probióticas - de $B$. bifidum, $B$. infantis, $B$. longum - ao queijo Crescenza foi testada. A adição de Bifidobacterium spp. afetou ligeiramente as características de textura do queijo e aquele contendo somente $B$. bifidum diferiu significativamente do queijo controle em relação ao sabor. A intensidade do sabor dos queijos com $B$. bifidum e $B$. longum adicionados individualmente foram ligeiramente maiores, em comparação ao controle (Gobbetti et al., 1997).

O tempo de armazenamento de diferentes queijos contendo probióticos estudados variou, principalmente, em função do tipo de queijo (maturado ou fresco, período e temperatura de maturação, etc.), da cultura adicionada e do inóculo dessa cultura. Assim, a sobrevivência de B. lactis e de $L$. acidophilus em queijo Gouda foi de 9 semanas (Gomes, Vieira, Malcata, 1998); de B. bifidum Bb02 e de B. longum Bb46 em queijo Canestrato-Pugliese foi de 56 dias (Corbo et al., 2001); de L. acidophilus e de Bifidobacterium spp. em queijo maturado Festivo com teor reduzido de gordura, após 13 semanas de maturação, foi de 16 semanas (Ryhänen, Pihlanto-Leppälä, Pahkala, 2001); de $B$. breve e de $B$. longum em queijo fresco foi de 15 dias (Roy, Mainville, Mondou, 1997); de uma combinação de cepas de $B$. bifidum e $L$. acidophilus em queijo fresco argentino foi de 60 dias (Vinderola et al., 2000b) e de $L$. acidophilus e de L. paracasei em queijo fresco brasileiro 
minas frescal foi de 21 dias (Jurkiewicz, 1999; Buriti et al., 2005; Buriti, Rocha, Saad, 2005; Souza et al., 2008).

A fim de se produzir um alimento mais saudável, ou seja, com propriedade probiótica aliada à baixa concentração de gordura, Ryhänen, Pihlanto-Leppälä e Pahkala (2001) testaram a sobrevivência de L. acidophilus e Bifidobacterium spp. em queijo maturado Festivo, com baixo teor de gordura. A diminuição de gordura não afetou as características organolépticas do produto, com boa aceitação geral na avaliação sensorial. Os probióticos permaneceram viáveis por até 7 meses, em concentrações iguais ou superiores a $10^{6}$ ufc g-1 , satisfazendo a concentração mínima necessária para efeito probiótico. Paralelamente, o processamento de queijo de leite de cabra com a adição das culturas probióticas de B. lactis e de L. acidophilus resultou na obtenção de um produto com boas características de sabor e textura, com populações finais desses microrganismos acima de $10^{6} \mathrm{ufc} \mathrm{g}^{-1}$ (Gomes, Malcata, 1999).

No Brasil, vários estudos foram realizados com queijo minas frescal, que revelaram populações de probióticos superiores a $10^{6} \mathrm{ufc} \mathrm{g}^{-1}$ durante o armazenamento refrigerado do produto por até 21 dias. O queijo mostrou-se veículo apropriado dos seguintes probióticos testados: $L$. paracasei LBC-82 (Buriti et al., 2005), L. acidophilus La5 (Buriti, Rocha, Saad, 2005), cultura ABT $-L$. acidophilus $\mathrm{La}-5+B$. animalis $\mathrm{Bb}-12+$ Streptococcus thermophilus (Buriti et al., 2007b) e L. acidophilus La-5 + S. thermophilus (Souza et al., 2008).

A viabilidade de L. acidophilus, assim como de $L$. paracasei, em queijo minas frescal foi ligeiramente favorecida em queijos adicionados da cultura starter tipo $\mathrm{O}$, composta por Lactococcus lactis subsp. lactis e Lactococcus lactis subsp. cremoris, comparada à viabilidade em queijos acidificados diretamente com ácido lático. Entretanto, os queijos com cultura $\mathrm{O}$ apresentaram características sensoriais e de textura instrumental mais desfavoráveis, em virtude da diminuição excessiva de $\mathrm{pH}$ ao final do período de armazenamento (Buriti et al., 2005; Buriti, Rocha, Saad, 2005).

Estudos com queijos petit-suisse, produzidos com massa-base de queijo quark contendo o starter $S$. thermophilus e os probióticos L. acidophilus e B. lactis, também foram realizados. Maruyama et al. (2006) verificaram que as populações de probióticos mantiveram-se acima de 6,40 log ufc g ${ }^{-1}$ para L. acidophilus Lac4 e de 7,30 log ufc $\mathrm{g}^{-1}$ para $B$. animalis subsp. lactis BL04 (anteriormente classificada como $B$. longum), em diferentes formulações de queijo petit-suisse contendo combinações das gomas xantana, guar, carragena e pectina. Trabalhando com as mesmas cepas, Cardarelli et al. (2008) observaram, em queijos petit-suisse simbióticos contendo os prebióticos inulina, oligofrutose e/ou mel, que L. acidophilus e B. lactis estiveram sempre superiores a $6 \log$ ufc g-1 e a $7 \mathrm{ufc} \mathrm{g}^{-1}$, respectivamente, com o melhor desempenho apresentado por $B$. lactis durante todo o armazenamento (28 dias).

O emprego de L. paracasei em co-cultura com $S$. thermophilus em queijo fresco cremoso simbiótico foi estudado por Buriti, Cardarelli e Saad (2007) e Buriti et al. (2007a). Buriti, Cardarelli e Saad (2007) verificaram populações acima de $7 \log$ ufc g $^{-1}$ de L. paracasei durante 21 dias de armazenamento dos queijos simbióticos e probióticos, produzidos, respectivamente, com e sem a adição da fibra prebiótica inulina. No mesmo estudo, os microrganismos $L$. paracasei e $S$. thermophilus em cocultura contribuíram para a bioconservação dos queijos probióticos e simbióticos, tendo sido efetivos na inibição de contaminantes, incluindo coliformes totais, Staphylococcus spp. e Staphylococcus DNAse positivos (Buriti, Cardarelli, Saad, 2007). Adicionalmente, a fibra inulina melhorou as características sensoriais dos queijos simbióticos (Buriti, Cardarelli, Saad, 2008), não tendo sido degradada pelas culturas presentes durante o armazenamento do produto (Buriti et al., 2007a).

\section{As sobremesas com base láctea como produtos probióticos}

O congelamento e descongelamento em produtos probióticos mantidos congelados, como o frozen yogurt e o sorvete, causam injúrias às células, como morte celular, inibição do desenvolvimento e redução ou interrupção da atividade metabólica. Por outro lado, diversos estudos mostram que temperaturas mais baixas podem assegurar maior taxa de sobrevivência e que a mortalidade aumenta com o tempo de armazenamento (Alamprese et al., 2002).

Segundo Davidson et al. (2000), a baixa viabilidade de microrganismos probióticos em sobremesas fermentadas e geladas, como o frozen yogurt, deve-se, principalmente, à acidez do produto $(\mathrm{pH} \leq 4,5)$, à injúria pelo frio e à toxicidade do oxigênio, conseqüente à incorporação de ar ao produto durante a sua elaboração, para a obtenção de um overrun adequado. Com o intuito de diminuir os efeitos prejudiciais às bactérias, os autores sugeriram a utilização da microencapsulação. Shah e Ravula (2000) testaram a tecnologia da microencapsulação em partículas de alginato de cálcio e seu efeito sobre a viabilidade de $L$. acidophilus MJLA1 incorporado à sobremesa láctea fermentada e gelada, com bons resultados. Comparada ao produto com bactérias livres, a população do probiótico naquele com a bactéria encapsulada foi maior ao final de 12 semanas de armazenamento, com uma diminuição 2 a 3 ciclos $\log$ menor. 
A atividade metabólica das bactérias do iogurte ( $L$. delbrueckii ssp. bulgaricus e $S$. thermophilus) e das bactérias probióticas pode ocasionar mudanças químicas e, conseqüentemente, influenciar as características sensoriais do produto. O sabor ácido do frozen yogurt deve-se, principalmente, ao ácido lático (Davidson et al., 2000). Davidson et al. (2000) observaram que o frozen yogurt revelou-se um excelente veículo para a incorporação de bactérias probióticas e que o armazenamento sob congelamento teve pouca influência sobre a sobrevivência de $L$. delbrueckii ssp. bulgaricus e $S$. thermophilus. Os autores observaram, ainda, que a adição de probióticos ( $L$. acidophilus e $B$. longum) alterou minimamente o sabor e as características do produto.

Alamprese et al. $(2002,2005)$ estudaram a influência de Lactobacillus johnsonii La1 e de L. rhamnosus GG em sorvetes com diferentes formulações, com variações nas quantidades de açúcar e de gordura. Os autores observaram elevadas taxas de sobrevivências dos probióticos durante o armazenamento dos produtos por, respectivamente, 8 meses e 365 dias, sem decréscimo na população inicialmente inoculada ( 7 e $8 \log$ ufc g ${ }^{-1}$, respectivamente). As propriedades funcionais não foram influenciadas pela presença dos probióticos em ambos os estudos.

O sorvete, como veículo de probióticos também foi estudado por Basyigit, Kuleasan, Karahan (2006). Os autores testaram uma mistura de cepas de Lactobacillus acidophilus, L. agilis e L. rhamnosus de origem humana e verificaram que a viabilidade dos probióticos não foi alterada durante o armazenamento de sorvete por até 6 meses, independentemente da presença de açúcar ou aspartame como edulcorantes. Os autores ressaltaram que o emprego de adoçantes em sorvetes suplementados com culturas probióticas poderá contribuir para carrear esses microrganismos benéficos para pessoas com doenças como a diabetes e obesidade.

As sobremesas aeradas, como a musse, vêm ganhando espaço no mercado, sendo atualmente produzidas em escala industrial. Aragon-Alegro et al. (2007) desenvolveram uma musse probiótica e simbiótica de chocolate, verificando, dentre outros parâmetros, a sobrevivência de L. paracasei ssp. paracase $\mathrm{LBC} 82$, ao longo de seu armazenamento refrigerado. A diminuição de $\mathrm{pH}$ ao longo das 4 semanas de armazenamento do produto não foi suficiente para comprometer a sobrevivência do microrganismo probiótico, que manteve viabilidade acima de $7 \log$ ufc g $^{-1}$. Em outro estudo com musses de chocolate, entretanto, Borges, Ferreira e Costa (2004) observaram um decréscimo de 3 log da população de probióticos, após o vigésimo dia de armazenamento das musses adicionadas de $1 \%$ L. acidophilus livres. Com o emprego da mesma proporção de L. acidophilus micro- encapsulados no produto, os autores ainda observaram um decréscimo de $2 \log$ na população do probiótico.

Uma sobremesa bastante difundida no Brasil, o manjar branco ou manjar de coco, foi estudada por Corrêa, Castro e Saad (2008) como veículo para cepas de L. paracasei e $B$. lactis, isoladas ou em co-cultura. Naquele estudo, a sobrevivência de $B$. lactis isolado ou em co-cultura com $L$. paracasei sempre variou entre 7 e 7,5 $\log \mathrm{ufc} \mathrm{g}^{-1}$. A população de $L$. paracasei ao início do armazenamento do manjar branco foi menor, aproximadamente $6,5 \log \mathrm{ufc}^{-1}$, entretanto, alcançou até $8,6 \log$ ufc $^{-1}$ ao final do armazenamento na ausência de $B$. lactis.

\section{Outros laticínios como produtos probióticos}

Outro produto lácteo fermentado probiótico que merece destaque é o kefir, uma bebida fermentada produzida a partir de leite, por ação de bactérias láticas, leveduras e bactérias produtoras de ácido acético. Os microrganismos utilizados na elaboração do produto ficam contidos em grãos de kefir, uma massa de diferentes bactérias e leveduras embebida em uma matriz complexa de proteínas e carboidratos, a qual é recuperada ao final do processo fermentativo (Farnworth, Mainville, 2003). A composição microbiológica e química do kefir indica que ele é um produto probiótico complexo (Farnworth, 2005). Segundo Farnworth e Mainville (2003), apesar de ser tradicionalmente considerado benéfico à saúde, ainda não há evidências científicas confirmando os benefícios dos microrganismos do kefir à saúde. Entretanto, a capacidade de imunomodulação, resultante da ingestão oral do kefir já foi relatada (Vinderola et al., 2005).

\section{Produtos não lácteos como produtos probióticos}

O aumento do vegetarianismo levou a uma demanda por produtos isentos de ingredientes provenientes de animais (Heenan et al., 2004). Nesse contexto, a soja aparece como um substituto ideal para o consumo, promovendo a saúde através de características nutricionais intrínsecas (Behrens, Roig, Silva, 2004). Entretanto, para que um produto exerça um papel sobre a saúde, não basta que ele possua características nutricionais vantajosas. É preciso que ele chegue até o consumidor, o que, por sua vez, depende do alimento apresentar um sabor favorável e, de maneira geral, propriedades atrativas (Behrens, Roig, Silva, 2004 ; Heenan et al., 2004).

Uma maneira de se melhorar a qualidade sensorial de extrato solúvel de soja é através da fermentação lática, aliada à suplementação com sacarose, glicose e lactose. (Behrens, Roig, Silva, 2004). O processo tecnológico da 
fermentação é conhecido por aumentar o valor nutricional e, ao mesmo tempo, melhorar a aceitabilidade dos produtos derivados da soja. A utilização de fungos para a fermentação já é bastante aplicada. Entretanto, existe, ainda, a possibilidade de se usar bactérias probióticas como culturas starter (Rossi et al., 1999).

Produtos derivados da soja têm se revelado veículos apropriados de culturas probióticas. O "leite de soja", mais apropriadamente chamado de extrato solúvel de soja, é uma bebida bastante popular em países asiáticos e seu consumo tem aumentado na América do Norte. O grão de soja é rico em proteínas de alta qualidade e, também, contém oligossacarídeos, como a rafinose e a estaquiose, que não são digeridos pelos humanos, podendo causar flatulência (Liener, 1994). A fermentação do extrato solúvel de soja com bactérias probióticas traz benefícios múltiplos, no sentido de reduzir os açúcares causadores de flatulência e conservar melhor o produto, contribuindo também, para a saúde do consumidor (Champagne, Gardner, Roy, 2005). Wang, Yu e Chou (2004) verificaram uma redução na quantidade desses oligossacarídeos em extrato solúvel de soja fermentado por culturas mistas de bifidobactérias e bactérias láticas. Adicionalmente, as bactérias láticas e bifidobactérias sobreviveram melhor no produto liofilizado quando comparado ao produto submetido à secagem em spray-dryer.

Segundo Rossi et al. (1999), o extrato solúvel de soja é um meio satisfatório para as bactérias láticas que conseguem metabolizar os carboidratos presentes nesse veículo. Os autores relataram que a suplementação do extrato solúvel de soja com soro de leite em pó promoveu a multiplicação de bactérias probióticas como E. faecium CRL 183, uma bactéria capaz de reduzir a quantidade de colesterol do meio. Os autores relataram, ainda, que a adição de Lactobacillus jugurti em co-cultura com E. faecium melhorou o sabor do produto final.

Heenan et al. (2004) testaram a sobrevivência de cepas probióticas em sobremesa não fermentada vegetariana congelada ( $\mathrm{pH}$ neutro). O congelamento do produto resultou em uma diminuição na viabilidade de $L$. rhamnosus 100-C e Sacharomyces boulardii 74012. Por outro lado, as cepas de L. acidophilus MJLA 1, L. paracasei ssp. paracasei Lp-01, B. lactis BDBB2 e $B$. lactis $\mathrm{Bb}-12$ permaneceram com populações acima de 7 log ufc g-1 no produto, ao longo de seu armazenamento por até 28 dias. Os autores verificaram que a sobremesa congelada com L. acidophilus não se diferenciou sensorialmente da sobremesa controle, enquanto que aquela adicionada de levedura desenvolveu aromas indesejáveis durante $\mathrm{o}$ armazenamento.

Em um estudo realizado com uma emulsão adicionada de culturas probióticas de $L$. casei e $B$. infantis, Charteris et al. (2002) observaram que, após 24 horas de armazenamento refrigerado a $4^{\circ} \mathrm{C}$, as populações de $\mathrm{L}$. $\mathrm{Ca}$ sei foram de $7,0 \times 10^{7} \mathrm{ufc}^{-1}$, enquanto que as populações

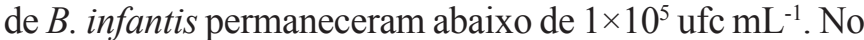
entanto, populações de $4,5 \times 10^{8}$ e $1,0 \times 10^{6} \mathrm{ufc}^{\mathrm{mL}^{-1}}$ de $L$. casei $\mathrm{e} B$. infantis, respectivamente, foram observadas quando foram testadas diferentes composições da fase aquosa, contendo diferentes ingredientes, como L-cisteína, alginato de sódio e soro de leite em pó.

Champagne, Gardner e Roy (2005) enumeraram outros produtos que vêm sendo estudados quanto ao seu potencial como veículo de microrganismos probióticos, incluindo maionese, carnes, alimentos infantis, produtos de confeitaria, patês, extratos de sementes vegetais, suco de pepino, produtos de peixe e kimchi. Kimchi é um produto vegetal fermentado de origem coreana. A fermentação, nesse caso, é realizada em um recipiente de pedra, em salmoura, por ação de bactérias láticas, utilizando-se, predominantemente, repolho e/ou rabanete como matéria-prima (Kwon, Kim, 2003).

\section{Considerações finais}

A evolução acelerada dos conhecimentos científicos sobre a atuação dos probióticos veiculados por produtos lácteos e por determinados produtos não-lácteos sobre a saúde do hospedeiro certamente resultará na ampliação do leque de opções de produtos probióticos disponíveis ao consumidor. Aliado a esse fato, o consumidor mais consciente e com estilo de vida equilibrado opta, cada vez mais, por produtos que, ao mesmo tempo, resultem em benefícios à saúde e sejam atrativos do ponto de vista sensorial. Conseqüentemente, o mercado desses produtos tende a ser cada vez mais competitivo.

Assim sendo, o que se espera para o futuro é que as inovações resultem em produtos probióticos mais diversificados que visem contribuir com a melhoria da saúde do consumidor. A combinação dos avanços genéticos com informações mais completas sobre os genomas aumenta as possibilidades futuras para o desenvolvimento de cepas probióticas mais eficazes. A manipulação genética, no sentido de desenvolvimento das culturas probióticas, também, tem o potencial de aumentar a sua viabilidade mediante a sua exposição a condições adversas, como aquelas encontradas durante o desenvolvimento de alimentos funcionais ou durante o trânsito intestinal. Entretanto, é necessário salientar que a eficácia e a segurança dessas cepas devem ser detalhadamente testadas (Ross, Desmond, Stanton, 2005).

Adicionalmente, a pesquisa centralizada na industrialização de produtos será voltada ao prolongamento da vida-de-prateleira dos produtos probióticos e na probabi- 
lidade de sobrevivência durante a passagem pelo trato gastrintestinal. Com isso, os esforços estarão voltados para a otimização da capacidade de adesão e o desenvolvimento de procedimentos apropriados de elaboração, manipulação e embalagem, no sentido de assegurar que os benefícios esperados cheguem ao consumidor. A fixação de padrões de identidade para produtos alimentícios contendo culturas probióticas será útil para acelerar o desenvolvimento e a disponibilidade desses produtos (Parvez et al., 2006). A tendência em se estudar o efeito dos alimentos probióticos, ao invés de apenas as bactérias probióticas, é necessária para aumentar a confiança do consumidor e dará maior credibilidade aos benefícios à saúde dos produtos probióticos (Mättö et al., 2006).

\section{CONCLUSÕES}

Diversos produtos lácteos probióticos vêm sendo desenvolvidos, principalmente fermentados e alguns não fermentados, além de alguns não-lácteos, como é o caso de produtos à base de soja. Produtos alimentícios como os laticínios são importantes para a sobrevivência dos probióticos ao suco gástrico, particularmente por seu efeito tamponante e protetor. É importante que os produtos probióticos contenham cepas bem caracterizadas, no sentido de compreender os fatores determinantes sobre a funcionalidade probiótica e os benefícios do hospedeiro.

A seleção de cepas probióticas deve ser direcionada aos efeitos atribuídos desejáveis para o produto específico ou para a população-alvo daquele produto. Adicionalmente, bactérias probióticas utilizadas na produção em escala industrial e de processamento devem ser bem caracterizadas e apropriadas para cada tipo de produto, bem como manter-se com boa viabilidade durante o seu armazenamento. Esses pré-requisitos representam desafios tecnológicos significativos e bastante promissores, tendo em vista que os consumidores mais conscientes e com estilo de vida equilibrado optam, cada vez mais, por produtos que, ao mesmo tempo, resultem em benefícios à saúde e sejam sensorialmente atrativos. No entanto, estes produtos acabam sendo mais caros, devido ao custo mais elevado para a sua produção e à sua alegação funcional, o que acaba por direcioná-los a um público diferenciado. Infelizmente, no caso de países como o Brasil, o acesso aos alimentos probióticos ainda é restrito às pessoas com maior poder aquisitivo, independentemente do nível de consciência em relação a um estilo de vida saudável. Dessa forma, a acessibilidade desses produtos para toda a população torna-se outro grande desafio.

\section{ABSTRACT
Overcoming hurdles through innovation, persistence and creativeness in the development of probiotic foods

The aim of probiotic products is to achieve a balanced intestinal microbiota that will impact favorably on the consumer health. An adequate strain selection must be carried out to manufacture probiotic food products. This selection should guarantee adequate probiotic survival during the passage through the gastrointestinal tract, after retaining its viability in the target product, both during manufacture and storage, in addition to providing the product with suitable technological properties. The food matrix to be selected for the incorporation of probiotic strains should be carefully studied for the adequate probiotic strain-food matrix pair selection, especially for fermented products, in which probiotic growth might result in atypical or even undesirable changes. Compatibility of the selected strains and adaptability to the food must also be verified. These prerequisites are major technological challenges, as many probiotic strains are sensitive to oxygen, heat and acids. A number of probiotic dairy products, mainly fermented ones, in addition to certain non-dairy products have been developed. The main challenges faced during the development of these products and storage are discussed in the present review.

UNITERMS: Probiotics. Functional foods. Lactobacillus. Bifidobacterium. Synbiotics. Prebiotics.

\section{AGRADECIMENTOS}

As autoras agradecem à Fundação de Amparo à Pesquisa do Estado de São Paulo (FAPESP) (Processos 05/ 51317-8, 05/50045-4, 04/13597-6 e 06/51297-0) e à Coordenação de Aperfeiçoamento de Pessoal de Nível Superior (CAPES) pelo auxílio financeiro e bolsas.

\section{REFERÊNCIAS BIBLIOGRÁFICAS}

\section{AGÊNCIA NACIONAL DE VIGILÂNCIA SANITÁRIA.}

Comissões tecnocientíficas de sssessoramento em alimentos funcionais e novos alimentos. Recomendações da comissão já aprovadas pela diretoria de alimentos em toxicologia. Disponível em: http://www.anvisa.gov.br/ alimentos/alimentos/ comissões/tecno.htm. Acesso em: 20 dez. 2001. 
AGÊNCIA NACIONAL DE VIGILÂNCIA SANITÁRIA. Alimentos com alegações de propriedades funcionais e ou de saúde, novos alimentos/ingredientes, substâncias bioativas e probióticos: lista de alegações de propriedade funcional aprovadas. Atualizado em agosto, 2007. Disponível em: http://www.anvisa.gov.br/alimentos/ comissoes/tecno_lista_alega.htm. Acesso em: 19 fev. 2008.

ALAMPRESE, C.; FOSCHINO, R.; ROSSI, M.; POMPEI, C.; CORTI, S. Effects of Lactobacillus rhamnosus GG addition in ice cream. Int. J. Dairy Technol., v.58, p.200206, 2005.

ALAMPRESE, C.; FOSCHINO, R.; ROSSI, M.; POMPEI, C.; SAVANI, L. Survival of Lactobacillus johnsonii La1 and influence of its addition in retail-manufactured ice cream produced with different sugar and fat concentrations. Int. Dairy J., v.12, p.201-208, 2002.

ALMEIDA, K.E.; BONASSI, I.A.; ROÇA, R.O. Características físicas e químicas de bebidas lácteas fermentadas e preparadas com soro de queijo minas frescal. Ciênc. Tecnol. Aliment., v.21, p.187-192, 2001.

ARAGON-ALEGRO, L.C.; ALEGRO, J.H.A.; CARDARELLI, H.R.; CHIU, M.C.; SAAD, S.M.I. Probiotic and synbiotic chocolate mousse. $L W T-$ Food Sci. Technol., v.40, p.669-675, 2007.

ARVANITOYANNIS, I.S.; HOUWELINGENKOUKALIAROGLOU, M.V. Functional foods: a survey of health, claims, pros and cons, and current legislation. Crit. Rev. Food Sci. Nutr., v.45, p. 385-404, 2005.

AWAISHEH, S.S.; HADDADIN, M.S.Y.; ROBINSON, R.K. Incorporation of selected nutraceuticals and probiotic bacteria into a fermented milk. Int. Dairy J., v.15, p.1184-1190, 2005.

BASYIGIT, G..; KULEASAN, H.; KARAHAN, A.G. Viability of human-derived probiotic lactobacilli in ice cream produced with sucrose and aspartame. $J$. Microbiol. Biotechnol., v.33, p.796-800, 2006.

BEHRENS, J.H.; ROIG, S.M.; SILVA, M.A.A.P. Fermentation of soymilk by commercial lactic cultures: development of a product with market potential. Acta Aliment., v.33, p.101-109, 2004.
BERGAMINI, C.V; HYNES, E.R; QUIBERONI, A.; SUÁREZ, V.B.; ZALAZAR, C.A. Probiotic bacteria as adjunct starters: influence of the addition methodology on their survival in a semi-hard Argentinean cheese. Food Res. Int., v.38, p.597-604, 2005.

BLANCHETTE,L.; ROY,D.; BELANGER, G.; GAUTHIER, S.F. Production of cottage cheese using dressing fermented by bifidobacteria. J. Dairy Sci., v.79, p.8-15, 1996.

BORGES, J.Q., FERREIRA, S.R.S.S., COSTA, G.W. Cinética de sobrevivência de Lactobacillus acidophilus microencapsulados em matriz de alginato de cálcio e veiculados em musse de chocolate. In: CONGRESSO BRASILEIRO DE CIÊNCIA E TECNOLOGIA DE ALIMENTOS, 19, Recife, 2004. Resumos. Campinas: Sociedade Brasileira de Ciência e Tecnologia de Alimentos, 2004. p.66

BOYLSTON, T.D; VINDEROLA, C.G; GHODDUSI, H.B; REINHEIMER, J.A. Incorporation of bifidobacteria into cheeses: challenges and rewards. Int. Dairy J., v.14, p.375-387, 2004.

BRASIL. Portaria n ${ }^{0} 15$, de 30 de abril de 1999. O Ministério da Saúde institui junto à Câmara Técnica de Alimentos a Comissão de Assessoramento de Alimentos Funcionais e Novos Alimentos. Diário Oficial, Brasília, 14 maio 1999. Seção 2 .

BURITI, F.C.A.; CARDARELLI, H.R.; FILISETTI, T.M.C.C.; SAAD, S.M.I. Synbiotic potential of fresh cream cheese supplemented with inulin and Lactobacillus paracasei in co-culture with Streptococcus thermophilus. Food Chem., v.104, p.1605-1610, 2007 a.

BURITI, F.C.A.; CARDARELLI, H.R.; SAAD, S.M.I. Biopreservation by Lactobacillus paracasei in coculture with Streptococcus thermophilus in potentially probiotic and synbiotic fresh cream cheeses. J. Food Prot., v.70, p.228-235, 2007.

BURITI, F.C.A.; CARDARELLI, H.R.; SAAD, S.M.I. Textura instrumental e avaliação sensorial de queijo fresco cremoso simbiótico: implicações da adição de Lactobacillus paracasei e inulina. Rev. Bras. Ciênc. Farm., v.44, p.75-84, 2008. 
BURITI, F.C.A.; OKAZAKI, T.Y; ALEGRO, J.H.A.; SAAD, S.M.I. Effect of a probiotic mixed culture on texture profile and sensory performance of Minas fresh cheese in comparison with the traditional products. Arch. Latinoam. Nutr., v.57, p.179-185, 2007 b.

BURITI, F.C.A.; ROCHA, J.S.; ASSIS, E.G.; SAAD, S.M.I. Probiotic potential of Minas fresh cheese prepared with the addition of Lactobacillus paracasei. LWT - Food Sci. Technol., v.38, p.173-180, 2005.

BURITI, F.C.A.; ROCHA, J.S.; SAAD, S.M.I. Incorporation of Lactobacillus acidophilus in Minas fresh cheese and its implications for textural and sensorial properties during storage. Int. Dairy J., v.15, p.1279-1288, 2005.

BURNS, P.; PATRIGNANI, F.; SERRAZANETTI, D.; VINDEROLA， G.C.; REINHEIMER， J.A.; LANCIOTTI, R.; GUERZONI, M.E. Probiotic Crescenza cheese containing Lactobacillus casei and Lactobacillus acidophilus manufactured with highpressure homogenized milk. J. Dairy Sci., v.91, p.500512, 2008.

CAPELA, P.; HAY, T.K.C.; SHAH, N.P. Effect of cryoprotectants, prebiotics and microencapsulation on survival of probiotic organisms in yogurt and freeze-dried yogurt. Food Res. Int., v.39, p.203-211, 2006.

CARDARELLI, H.R.; BURITI, F.C.A.; CASTRO, I.A.; SAAD, S.M.I. Inulin and oligofructose improve sensory quality and increase the probiotic viable count in potentially synbiotic petit-suisse cheese. $L W T-$ Food Sci. Technol., v. 41, p. 1037-1046, 2008.

CHAMPAGNE, C.P.; GARDNER, N.J.; ROY, D. Challenges in the addition of probiotic cultures to foods. Crit. Rev. Food Sci. Nutr., v.45, p.61-84, 2005.

CHARTERIS, W.P.; KELLY, P.M.; MORELLI, L.; COLLINS, J.K. Ingredient selection criteria for probiotic microorganisms in functional dairy foods. Int. J. Dairy Technol., v.51, p.123-136, 1998a.

CHARTERIS, W.P.; KELLY, P.M.; MORELLI, L.; COLLINS, J.K. Development and application of an in vitro methodology to determine the transit tolerance of potentially probiotic Lactobacillus and Bifidobacterium species in the upper human gastrointestinal tract. J. Appl. Microbiol., v.84, p.759-768, 1998 b.
CHARTERIS, W.P.; KELLY, P.M.; MORELLI, L.; COLLINS, J.K. Edible table (bio)spread containing potentially probiotic Lactobacillus and Bifidobacterium species. Int. J. Dairy Technol., v.55, p.44-56, 2002.

CORBO, M.R.; ALBENZIO, M.; DEANGELIS, M.; SEVI, A.; GOBBETTI, M. Microbiological and biochemical properties of Canestrato Pugliese hard cheese supplemented with Bifidobacteria. J. Dairy Sci., v. 84, p.551-561, 2001.

CORRÊA, S.M.; CASTRO, I.A.; SAAD, S.M.I. Probiotic potential and sensory properties of coconut flan supplemented with Lactobacillus paracasei and Bifidobacterium lactis. Int. J. Food Sci. Technol., v.43, p.1560-1568, 2008.

DAIGLE, A.; ROY, D.; BÉLANGER, G.; VUILLEMARD, J.C. Production of probiotic cheese (Cheddar-like cheese) using enriched cream fermented by Bifidobacterium infantis. J. Dairy Sci., v.82, p.1081-1091, 1999.

DAVE, R.I.; SHAH, N.P. Ingredient supplementation effects on viability of probiotic bacteria in yogurt. J. Dairy Sci., v.81, p. 2804-2816, 1998.

DAVIDSON, R.H.; DUNCAN, S.E.; HACKNEY, C.R.; EIGEL, W.N.; BOLING, J.W. Probiotic culture survival and implications in fermented frozen yogurt characteristics. J. Dairy Sci., v.83, p.666-673, 2000.

DESAI, A.R.; POWELL, I.B.; SHAH, N.P. Survival and activity of probiotic lactobacilli in skim milk containing prebiotics. J. Food Sci., v.69, p.M57-M60, 2004.

DINAKAR, P.; MISTRY, V.V. Growth and viability of Bifidobacterium bifidum in Cheddar cheese. J. Dairy Sci., v.77, p.2854-2864, 1994.

DONKOR, O.N.; HENRIKSSON, A.; VASILJEVIC, T.; SHAH, N.P. Effect of acidification on the activity of probiotics in yoghurt during cold storage. Int. Dairy J., v.16, p.1181-1189, 2006.

DRAKE, M.A.; BOYLSTON, T.D.; SPENCE, K.D.; SWANSON, B.G. Chemical and sensory effects of a Lactobacillus adjunct in Cheddar cheese. Food Res. Int., v.29, p.381-387, 1996. 


\section{EUROPEANCOMMISSION CONCERTED ACTION ON} FUNCTIONAL FOOD SCIENCE IN EUROPE. Scientific Concepts of Functional Foods in Europe Consensus Document. Br. J. Nutr., v.81, n.4, suppl.1, p.S1-S27, 1999.

FARIA, C.P.; BENEDET, H.D.; LE GUERROUE, J.L. Parâmetros de produção de leite de búfala fermentado por Lactobacillus casei. Pesqui. Agropecu. Bras., v.41, n.3, p.511-516, 2006.

FARNWORTH, E.R. Kefir - a complex probiotic. Food Sci. Technol. Bull., v.2, n.1, p.1-17, 2005.

FARNWORTH, E.R.; MAINVILLE, I. Kefir: a fermented milk product. In: FARNWORTH, E.R., (Ed.). Handbook of fermented functional foods. Boca Raton: CRC Press, 2003. p.77-111.

FOOD AND AGRICULTURE ORGANIZATION OF THE UNITED NATIONS; WORLD HEALTH ORGANIZATION. Evaluation of health and nutritional properties of probiotics in food including powder milk with live lactic acid bacteria. Córdoba, 2001. 34p. Disponível em: <ftp://ftp.fao.org/es/esn/food/ probioreport_en.pdf $>$. Acesso em: 03 fev. 2005. [Report of a Joint FAO/WHO Expert Consultation].

FOOKS, L.J.; FULLER, R.; GIBSON, G.R. Prebiotics, probiotics and human gut microbiology. Int. Dairy J., v.9, p.53-61, 1999.

FULLER, R. Probiotics in man and animals. J. Appl. Bacteriol., v.66, p.365-378, 1989.

GARDINER, G.E.; BOUCHIER, P.; O'SULLIVAN, E.; KELLY, J.; COLLINS, J.K.; FITZGERALD, G.; ROSS, R.P.; STANTON, C. A spray-dried culture for probiotic Cheddar cheese manufacture. Int. Dairy J., v.12, p. 749 756, 2002.

GARDINER, G.E.; ROSS, R.P.; COLLINS, J.K.; FITZGERALD, G.; STANTON, C. Development of a probiotic Cheddar cheese containing human-derived Lactobacillus paracasei strains. Appl. Environ. Microbiol., v.64, p.2192-2199, 1998.
GARDINER, G.E.; ROSS, R.P.; WALLACE, J.M.; SCANLAN, F.P.; JAGERS, P.P.; FITZGERALD, G.F.; COLLINS, J.K.; STANTON, C. Influence of a probiotic adjunct culture of Enterococcus faecium on the quality of cheddar cheese. J. Agric. Food Chem., v.47, n.12, p.49074916, 1999.

GHODDUSI, H.B.; ROBINSON, R.K. The test of time. Dairy Ind. Int., v.61, n.7, p.25-28, 1996.

GIBSON, G.R., ROBERT, H.M., VAN LOO, J., RASTALL, R.A., ROBERFROID, M. B. Dietary modulation of the human colonic microbiota: updating the concept of prebiotics. Nutr. Res. Rev., v.17, p. 259-275, 2004.

GOBBETTI, M.; CORSETTI, A.; SMACCHI, E.; ZOCCHETTI, A.; De ANGELIS, M. Production of crescenza cheese by incorporation of bifidobacteria. $J$. Dairy Sci., v.81, p.37-47, 1997.

GOBBETTI, M.; MOREA, M.; BARUZZI, F.; CORBO, M.R.; MATARANTE, A.; CONSIDINE, T.; Di CAGNO, R.; GUINEE, T.; FOX, P.F. Microbiological, compositional, biochemical and textural characterisation of Caciocavallo Pugliese cheese during ripening. Int. Dairy J., v.12, p.511-523, 2002.

GOMES, A.M.P.; MALCATA, F.X. Use of small ruminants' milk supplemented with available nitrogen as growth media for Bifidobacterium lactis and Lactobacillus acidophilus. J. Appl. Microbiol., v.85, p. 839-849, 1998.

GOMES, A.M.P.; MALCATA, F.X. Bifidobacterium spp. and Lactobacillus acidophilus: biological, biochemical, technological and therapeutical properties relevant for use as probiotics. Trends Food Sci. Technol., v.10, p.139-157, 1999.

GOMES, A.M.P.; VIEIRA, M.M.; MALCATA, F.X. Survival of probiotic microbial strains in a cheese matrix during ripening: simulation of rates of salt diffusion and microorganism survival. J. Food Eng., v.36, p.281-301, 1998.

GROSSO, C.R.F.; FÁVARO-TRINDADE, C.S. Stability of free and immobilized Lactobacillus acidophilus and Bifidobacterium lactis in acidified milk and of immobilized B. lactis in yoghurt. Braz. J. Microbiol., v.35, p.151-156, 2004. 
GUARNER, F.; PERDIGON, G.; CORTHIER, G.; SALMINEN, S.; KOLETZKO, B.; MORELLI, L. Should yoghurt cultures be considered probiotic? $\mathrm{Br} . J$. Nutr., v.93, p.783-786, 2005.

HEENAN, C.N.;ADAMS, M.C.; HOSKEN, R.W.; FLEET, G.H. Survival and sensory acceptability of probiotic microorganisms in a nonfermented frozen vegetarian dessert. LWT-Food Sci. Technol., v.37, p.461-466, 2004.

HELLER, K.J.; BOCKELMANN, W.; SCHREZENMEIR, J.; deVRESE, M. Cheese and its potential as a probiotic food. In: FARNWORTH, E.R., Ed. Handbook of fermented functional foods. Boca Raton: CRC Press, 2003. p.203-225.

HOLS, P.; HANCY, F.; FONTAINE, L.; GROSSIORD, B.; PROZZI, D.; LEBLOND-BOURGET, N.; DECARIS, B.; BOLOTIN, A.; DELORME, C.; EHRLICH, S.D.; GUÉDON, E.; MONNET, V.; RENAULT, P.; KLEEREBEZEM, M. New insights in the molecular biology and physiology of Streptococcus thermophilus revealed by comparative genomics. FEMS Microbiol. Revi., v.29, p.435-463, 2005.

JURKIEWICZ, C.H. Avaliação das características microbiológicas, fisico-químicas e sensoriais de queijo minas frescal elaborado com culturas probióticas de Lactobacillus acidophilus. São Paulo, 1999. 134p. [Tese de Doutorado. Programa de Pós-Graduação em Ciência dos Alimentos. Faculdade de Ciências Farmacêuticas. Universidade de São Paulo].

KALANTZOPOULOS, G. Fermented products with probiotic qualities. Anaerobe, v.3, p.185-190, 1997.

KAPLAN, H.; HUTKINS, R.W. Fermentation of fructooligosaccharides by lactic acid bacteria and bifidobacteria. Appl. Environ. Microbiol., v.66, p.26822684, 2000.

KASK, S.; ADAMBERG, K.; ORLOWSKI, A.; VOGENSEN, F.K.; MØLLER, P.L.; ARDÖ, Y.; PAALME, T. Physiological properties of Lactobacillus paracasei, L. danicus and L. curvatus strains isolated from Estonian semi-hard cheese. Food Res. Int., v.36, p.1037-1046, 2003.
KIM, Y.; FAQIH, M.N.; WANG, S.S. Factors affecting gel formation of inulin. Carbohydr. Polym., v.46, p.135-145, 2001.

KLAVER, F.A.M., KINGMAN, F., WEERKAMP, A.H Growth and survival of bifidobacteria in milk. Neth. Milk Dairy J., v.47, p.151-164, 1993.

KRASAEKOOPT, W.; BHANDARI, B.; DEETH, H. Evaluation of encapsulation techniques of probiotics for yoghurt. Int. Dairy J., v.13, p.3-13, 2003.

KRISTO, E.; BILIADERIS, C.G.; TZANETAKIS, N. Modelling of rheological, microbiological and acidification properties of a fermented milk product containing a probiotic strain of Lactobacillus paracasei. Int. Dairy J., v.13, p.517-528, 2003.

KWON, H.; KIM, Y.K.L. Korean fermented foods: kimchi and doenjang. In: FARNWORTH, E.R.,(Ed.). Handbook offermented functional foods. Boca Raton: CRC Press, 2003. p.287-304.

LAMOUREUX, L.; ROY, D.; GAUTHER, S.F. Production of oligossacharides in yogurt containing Bifidobacteria and yogurt cultures. Am. Dairy Sci. Assoc., v.85, p.10581069,2002

LEAHY, S.C.; HIGGINS, D.G.; FITZGERALD, G.F.; VAN SINDEREN, D. Getting better with bifidobacteria. Appl. Microbiol., v.98, n.6, p.1303-1315, 2005.

LEROY, F.; DE VUYST, L. Lactic acid bacteria as functional starter cultures for the food fermentation industry. Trends Food Sci. Technol., v.15, p.67-78, 2004.

LIENER, I.E. Implications of antinutritional components in soybean foods. Crit. Rev. Food Sci. Nutr., v.34, p.31-67, 1994.

LOURENS-HATTINGH, A.; VILJOEN, B.C. Yogurt as probiotic carrier food. Int. Dairy J., v.11, p.1-17, 2001.

LUCAS, A.; SODINI, I.; MONNET, C.; JOLIVET, P.; CORRIEU, G. Probiotic cell counts and acidification in fermented milks supplemented with milk protein hydrolysates. Int. Dairy J., v.14, p. 47-53, 2004. 
MAKRAS, L.; VAN ACKER, G.; DE VUYST, L. Lactobacillus paracasei subsp. Paracasei 8700:2 degrades inulin-type fructans exhibiting different negrees of polymerization. Appl. Environ. Microbiol., v.71, p.6531-6537, 2005.

MANNING, T.S.; GIBSON, G.R. Prebiotics. Best Pract. Res. Clin. Gastroenterol.,v.18, p.287-298, 2004.

MARTÍNEZ-VILLALUENGA, C.; FRIAS, J.; VIDALVALVERDE, C.; GOMEZ, R. Raffinose family of oligosaccharides from lupin seeds as prebiotics: application in dairy products. J. Food Prot., v.68, p.12461252, 2005.

MARTÍNEZ-VILLALUENGA, C.; FRIAS, J.; GOMEZ, R.; VIDAL-VALVERDE, C. Influence of addition of rafinose family oligosaccharides on probiotic survival in fermented milk during refrigerated storage. Int. Dairy J., v.16, p.768774, 2006.

MARUYAMA, L.Y.; CARDARELLI, H.R.; BURITI, F.C.A.; SAAD, S.M.I. Textura instrumental de queijo petit-suisse potencialmente probiótico: influência de diferentes combinações de gomas. Ciênc. Tecnol. Aliment., v.26, p.386-393, 2006.

MATTILA-SANDHOLM, T.; MÄTTÖ, J.; SAARELA, M. Lactic acid bacteria with health claims - interactions and interference with gastrointestinal flora. Int. Dairy J., v.11, p.1-17, 1999.

MATTILA-SANDHOLM, T.; MYLLÄRINEN, P.; CRITTENDEN, R.; MOGENSEN, G.; FONDÉN, R.; SAARELA, M. Technological challenges for future probiotic foods. Int. Dairy J., v.12, p.173-182, 2002.

MÄTTÖ, J.; FONDÉN, R.; TOLVANEN, T.; VON WRIGHT, A.; VILPPONEN-SALMELA; SATOKARI, R.; SAARELA, M. Intestinal survival and persistence of probiotic Lactobacillus and Bifidobacterium strains administered in triple-strain yoghurt. Int. Dairy J., v.16, p.1174-1180, 2006.

Mc BREARTY, S.; ROSS, R.P.; FITZGERALD, G.F.; COLLINS, J.K.; WALLACE, J.M.; STANTON, C. Influence of two commercially available bifidobacteria cultures on Cheddar cheese quality. Int. Dairy J., v.11, p.599-610, 2001.
MENÉNDEZ, S.; CENTENO, J.A.; GODÍNEZ, R.; RODRÍGUEZ-OTERO, J.L. Effect of Lactobacillus strains on the ripening and organoleptic characteristics of Arzúa-Ulloa cheese. International J. Food Microbiol., v.59, p.37-46, 2000.

NINESS, K.R. Inulin and oligofructose: what are they? $J$. Nutr., v.129, suppl.7, p.1402S-1406S, 1999.

NOVIK, G.I.; SAMARTSEV, A.A.; ASTAPOVICH, N.I.; KAVRUS, M.A.; MIKHALYUK, A.N. Biological activity of probiotic microorganisms. Appl. Biochem. Microbiol., v.42, p.166-172, 2006.

OLIVEIRA, M.N.; DAMIN, M.R. Efeito do teor de sólidos e da concentração de sacarose na acidificação, firmeza e viabilidade de bactérias do iogurte e probióticas em leite fermentado. Ciênc. Tecnol. Aliment., v.23, supl., p.172176, 2003.

OLIVEIRA, M.N.; SIVIERI, K.; ALEGRO, J.H.A.; SAAD, S.M.I. Aspectos tecnológicos de alimentos funcionais contendo probióticos. Rev. Bras. Ciênc. Farm., v.38, p.121, 2002.

ONG, L.; HENRIKSSON, A.; SHAH, N.P. Development of probiotic cheddar cheese containing Lactobacillus acidophilus, Lb casei, Lb paracasei and Bifidobacterium spp. and the influence of these bacteria on proteolytic patterns and production of organic acid. Int. Dairy J., v.16, p.446-456, 2006.

OSTLIE, H.M.; HELLAND M.H.; NARVHUS, J.A. Growth and metabolism of selected strains of probiotic bacteria in milk. Int. J. Food Microbiol., v.87, p.17-27, 2003.

OSTLIE, H.M.; TREIMO, J.; NARVHUS, J.A. Effect of temperature on growth and metabolism of probiotic bacteria in milk. Int. Dairy J., v.15, p.989-997, 2005.

PARVEZ, K.A.; MALIK, S.; KANG S.AH; KIM, H.-Y. Probiotics and their fermented food products are beneficial for health. J. Appl. Bacteriol., v.100, p.1171-1185, 2006.

PICARD, C.; FIORAMONTI, J.; FRANCOIS, A.; ROBINSON, T.; NEANT, F.; MATUCHANSKY, C. Review article: bifidobacteria as probiotic agents physiological effects and clinical benefits. Aliment. Pharmacol. Ther., v.22, p.495-512, 2005. 
ROBERFROID, M.B. Concepts in functional foods: the case of inulin and oligofructose. J. Nutr., v.129, suppl.7, p.1398S-1401S, 1999.

ROBERFROID, M.B. Introducing inulin-type fructans. $B r . J$. Nutr., v.93, suppl. 1, p.S13-S25, 2005.

ROBERFROID, M.B. Prebiotics: the concept revisited. $J$. Nutr., v.137, p.830S-837S, 2007.

ROSS, R.P.; DESMOND, C.; STANTON, C. Overcoming the technological hurdles in the development of probiotic foods. J. Appl. Microbiol., v.98, p.1410-1417, 2005.

ROSS, R.P.; STANTON, C.; HILL, C.; FITZGERALD, G.F.; COFFEY, A. Novel cultures for cheese improvement. Trends Food Sci. Technol., v.11, p.96-104, 2000.

ROSSI, E.A.; VENDRAMINI, R.C.; CARLOS, I.Z.; PEI, Y.C.; VALDEZ, G.F. Development of novel fermented soymilk product with potential probiotic properties. Eur. Food Res. Technol., v.209, p. 305-307, 1999.

ROY, D.; MAINVILLE, I.; MONDOU, F. Selective enumeration and survival of bifidobacteria in fresh cheese. Int. Dairy J., v.7, p.785-793, 1997.

RYHÄNEN, E.L; PIHLANTO-LEPPÄLÄ, A; PAHKALA, E. A new type of ripened, low-fat cheese with bioactive properties. Int. Dairy J., v.11, p.441-447, 2001.

SAAD, S.M.I. Probióticos e Prebióticos: o estado da arte. Rev. Bras. Ciênc. Farm., v.42, p.1-16, 2006.

SANDERS, M.E. Overview of functional foods: emphasis on probiotic bacteria. Int. Dairy J., v.8, p.341-347, 1998.

SANDERS, M.E. Probiotics: considerations for human health. Nutr. Rev., v.61, p.91-99, 2003.

SHAH, N.P. Functional cultures and health benefits. Int. Dairy J., v.17, p.1262-1277, 2007.

SHAH, N.P. Probiotic bactéria: selective enumeration and survival in dairy foods. J. Dairy Sci., v.83, p.894-907, 2000 .

SHAH, N.P.; RAVULA, R.R. Microencapsulation of probiotic bacteria and their survival in frozen fermented dairy desserts. Aust. J. Dairy Technol., v.55, p.139-144, 2000.
SOUZA, C.H.B.; BURITI, F.C.A.; BEHRENS, J.H.; SAAD, S.M.I. Sensory evaluation of probiotic Minas fresh cheese with Lactobacillus acidophilus added solely or in coculture with a thermophilic starter culture. Int. J. Food Sci. Technol., v.43, p.871-877, 2008

STANTON, C.; DESMOND, C.; COAKLEY, M.; COLLINS, J.K.; FITZGERALD G.F.; ROSS, R.P. Challenges facing development of probiotic-containing functional foods. In: FARNWORTH, E.R., (Ed.). Handbook of fermented functional foods. Boca Raton: CRC Press, 2003. p.27-58.

STANTON, C.; GARDINER, G.; LYNCH, P.B.; COLLINS, J.K.; FITZGERALD, G.; ROSS, R.P. Probiotic cheese. Int. Dairy J., v.8, p.491-496, 1998.

STANTON, C.; ROSS, R.P.; FITZGERALD, G. F.; VAN SINDEREN, D. Fermented functional foods based on probiotics and their biogenic metabolites. Curr. Opin. Biotechnol., v.16, p.196-203, 2005.

SVENSSON, U. Industrial perspectives. In: TANNOCK, G.W. (Ed.) Probiotics: a critical review. Wymondham: Horizon Scientific Press, 1999. p.57-64.

TAMIME, A.Y.; MARSHALL, V.M.E.; ROBINSON, R.K. Microbiological and technological aspects of milks fermented by bifidobacteria. J. Dairy Res., v.62, p.151187, 1995.

TANNOCK, G.W. Studies of the intestinal microflora: a prerequisite for the development of probiotics. Int. Dairy J., v.8, p.527-533, 1998.

THAMER, K.G.; PENNA, A.L.B. Efeito do teor de soro, açúcar e de frutooligossacarídeos sobre a população de bactérias lácticas probióticas em bebidas fermentadas. Rev. Bras. Ciênc. Farm., v.41, p.393-400, 2005.

VAN DE WATER, J. Yogurt and immunity: the health benefits of fermented milk products that contain lactic acid bacteria. In: FARNWORTH, E.R., (Ed.). Handbook of fermented functional foods. Boca Raton: CRC Press, 2003. p.113-144.

VAN-LOO, J. The specificity of the interaction with intestinal bacterial fermentation by probiotics determines their physiological efficacy. Nutr. Res. Rev., v.17, p.89-98, 2004. 
VINDEROLA, C.G.; DUARTE, J.; THANGAVEL, D.; PERDIGÓN, G.; FARNWORTH, E.; MATAR, C. Immunomodulating capacity of kefir. J. Dairy Res., v.72, p.195-202, 2005.

VINDEROLA, C.G.; GUEIMONDE, M.; DELGADO, T.; REINHEIMER, J.A.; REYE-GAVILÁN, C.G. Characteristics of carbonated fermented milk and survival of probiotic bacteria. Int. Dairy J., v.10, p.213-220, 2000a.

VINDEROLA, C.G.; MOCCHIUTTI, P.; REINHEIMER, J.A. Interactions among lactic acid starter and probiotic bacteria used for fermented dairy products. J. Dairy Sci., v.85, p.721-729, 2002.

VINDEROLA, C.G.; PROSELLO, W.; GHIBERTO, D.; REINHEIMER, J.A. Viability of probiotic (Bifidobacterium, Lactobacillus acidophilus and Lactobacillus casei) and nonprobiotic microflora in Argentinean fresco cheese. J. Dairy Sci., v.83, p.19051911, 2000b.

VINDEROLA, C.G.; REINHEIMER, J.A. Enumeration of Lactobacillus casei in the presence of L. acidophilus, bifidobacteria and lactic starter bacteria in fermented dairy products. Int. Dairy J., v.10, p.271-275, 2000.
VINDEROLA, C.G.; REINHEIMER, J.A. Lactic acid starter and probiotic bacteria: a comparative "in vitro" study of probiotic characteristics and biological barrier resistance. Food Res. Int., v.36, p.895-904, 2003.

WANG, Y.C.; YU, R.C.; CHOU, C.C. Viability of lactic acid bacteria and bifidobacteria in fermented soymilk after drying, subsequent rehydration and storage. Int. J. Food Microbiol., v.93, p.209-217, 2004.

WELLS, A.L.; SAULNIER, D.M.A.; GIBSON, G.R. Gastrointestinal microflora and interactions with gut flora. In: GIBSON, G.R.; ROBERFROID, M.B., (Eds.). Handbook of prebiotics. Boca Raton: CRC Press, 2008. p.14-38.

ZACARCHENCO, P.B.; MASSAGUER-ROIG, S. Avaliação sensorial, microbiológica e de pós-acidificação durante a vida-de-prateleira de leites fermentados contendo Streptococcus thermophilus, Bifidobacterium longum e Lactobacillus acidophilus. Ciênc. Tecnol. Aliment., v.24, p.674-679, 2004.

Recebido para publicação em 15 de março de 2007 Aceito para publicação em 16 de abril de 2008 